\title{
Biomarkers of healthy and diseased pulp and periapical tissue: A review
}

\begin{abstract}
:
Establishing an accurate diagnosis is the first and prime requisite, in initiating the correct treatment, but unfortunately due to the limitations of the diagnostic procedure, this step can be highly confounding. Biological marker serves as a parameter, that is indicative of underlying physiology and health of the tissue. Healthy and diseased pulp and periapical tissue, tend to reflect physiologic and pathologic agents, which on isolation and estimation, can help diagnose, the condition more conclusively. Use of these agents, along with signs, symptoms, result of various tests, can aid in establishing the condition, more precisely. This review article focuses upon, identification of biomarkers, that play important role in pathogenesis of dental caries, pulpal and periapical pathosis and help to diagnose the pathological and healthy condition accurately, thus guide decisions, regarding clinical treatment.
\end{abstract}

Key words: Biological Products, Biomarkers, Dental Caries, Dental Pulp, Diagnostic Tests

\section{Introduction:}

Establishing an accurate diagnosis is the first and prime requisite in initiating the correct treatment but unfortunately due to the limitations of the diagnostic procedure this step can be highly confounding.[1] In this situation biomarkers assumes important. For diagnosing endodontic conditions, clinical symptoms are considered rather than histologic findings since histologic pulp tissue examination is not possible in most of these situations. Hence identification of specific biomarker could help in establishing more accurate diagnosis.

Biological marker serves as a parameter that is indicative of underlying physiology and health of the tissue. It is measurable as well as quantifiable. Bence-Jones protein where probably the first recognized biomarker.[2] Thereafter an attempt has been made to diagnose various diseases on the basis of their isolated biomarkers.

Diagnosis of the diseases of pulp and periradicular area is primarily based upon the clinical findings along with the result of the radiograph and other test. Their combination leads to the establishment of the clinical diagnosis but slight mistake in

\begin{tabular}{|l|l|}
\hline \multicolumn{3}{|c|}{ Access this article online } \\
\hline \multirow{2}{*}{$\begin{array}{l}\text { Website: } \\
\text { www.ujds.in }\end{array}$} & Quick Response Code \\
\hline $\begin{array}{l}\text { DOI: } \\
\text { https://doi.org/10.21276/10.21276/ujds.2020.6.2.14 }\end{array}$ & \\
\hline
\end{tabular}

any of these can alter the diagnosis. Identification of biomarkers, that play important role in pathogenesis of dental caries, pulpal and periapical pathosis, helps to diagnose the pathological condition accurately and guide decisions regarding clinical treatment.[3] This review article is an attempt to analyze the available literature on biomarkers of endodontic diseases.

\section{Systematic Review:}

Eligibility Criteria and Literature Search: For establishing the current status of the identifiable biomarkers of endodontic diseases a search for articles was carried out on the internet using these sites; PubMed, Google scholar, ResearchGate, EBSCOhost. The search was carried out using the terms; Diseases of pulp, Periradicular area, Pulpitis, Acute pulpitis,

\section{AIN A, ${ }^{2}$ AURWADE $V,{ }^{3}$ BAHUGUNA $R,{ }^{4}$ AGARWAL A ${ }_{1,2,4}$ Department of Conservative Dentistry and Endodontics, TMDCRC, Moradabad ${ }^{3}$ Department of Pedodontics and Preventive Dentistry, TMDCRC, Moradabad}

Address for Correspondence: Dr. Vinod Neminath Aurwade Teerthanker Mahaveer Dental College and Research Center Moradabad, U.P., India. E mail : vinodaurwade555@gmail.com

Received : 18 July 2020, Published : 31 August 2020

How to cite this article: Jain, A., Aurwade, V., Bahuguna, R., \& Agarwal, A. (2020). Biomarkers of Healthy and Diseased Pulp and Periapical Tissue: A Review. UNIVERSITY JOURNAL OF DENTAL SCIENCES, 6(2): 94-100. 
Irreversible pulpitis, Painful pulpitis, Periodontitis, Apical periodontitis, Internal and external tooth resorption, biological markers, inflammation mediators, dentinal fluid, and gingival crevicular fluid and their various combinations. Inclusion Criteria: Out of the various articles found in the search, research studies or experimental studies conducted on human's, review articles, published during January 2001 till December 2019 were included. 322 articles were found matching the search criteria. Out of these, 86 articles were selected for this review since the remaining 236 met one of the other exclusion criteria.

Exclusion Criteria: Studies carried out on animals, thesis or interruptive articles were excluded.

\section{Biomarkers in healthy Pulp:}

Osteocalcin (OCN): Odontoblasts produce glycoprotein OCN which is stored in the dentin matrix.[4] It has been used as a mineralization marker for odontoblast / osteoblast-like differentiation in dental pulp stem cells.[5]

Thyrotropin-Releasing Hormone (TRH) - Degrading Enzyme (DE): Also known as pyroglutamyl peptidase II, it is extracellularly directed and acts to stop peptide-mediated cell signaling. TRH-DE was isolated in the dental pulp by microarray analysis and real-time RT-PCR analysis.[6]

Matrix metalloproteinase (MMP): MMPs are synthesized by cells of the connective tissue, like fibroblasts, osteoblasts, odontoblasts and secreted into the extracellular matrix. In pulp, multiple MMP have been detected by polymerase chain reaction (PCR) and immunohistochemistry.

Bone Morphogenic Protein (BMP-2): Expression of the BMP2 occurs during tooth cytodifferentiation in postnatal odontoblasts and ameloblasts from birth to about 20 days after birth.[7]

Bone sialoprotein (BSP): is an essential non-collagenous protein produced in mineralized connective tissue. Its expression is essential for the mineralization of dentin and cementum.[8]

\section{Biomarkers in healthy Periapical Tissue:}

Matrix metalloproteinases (MMPs): are also responsible for the deterioration and remodeling of tissues. In health, the periodontal ligament system is protected from MMP mediated proteolytic attack by metalloproteinase tissue inhibitors (TIMP).
Pyridinoline cross-linked carboxyterminal telopeptide of type I collagen: Type I collagen is the primary form of collagen present in mineralized tissues. Increased ICTP levels are related to most pathogens like T. P. gingivalis, forsythensis, P. intermedia, and T. denticola.[9]

Osteocalcin: a non-collagenous protein, is located primarily in mineralized tissues, formed by osteoblasts, and helps in bone remodeling. Its level, during gingivitis remains unchanged, whereas it rises in periodontitis.[10]

Calprotectin: a protein that binds calcium and zinc, has antimicrobial and antifungal activity and plays a critical role in inflammation. Increased Calprotectin production at the site of inflammation, defends epithelial cells from bacterial invasion, especially P. gingivalis.[11]

Osteonectin: a protein, acidic in nature, containing cysteine, plays a vital role in the early mineralization process. Hence it can serve as a sensitive marker for periodontitis detection.

Osteopontin (OPN): is produced by both osteoblasts and osteoclasts. At the clear zone, the site of osteoclast attachment, concentration of OPN is higher, which helps in remodeling bones. OPN concentration in periodontitis increases.[12]

Table 1: Biomarkers of Healthy Pulp and Periapical Tissue.

\begin{tabular}{|c|c|c|}
\hline Biomarker & Role & Studies \\
\hline Osteocalcin (OCN) & $\begin{array}{l}\text { One of the reparative } \\
\text { molecules and its production } \\
\text { occurs in reaction to dental } \\
\text { pulp injury and also helps in } \\
\text { bone remodeling. }\end{array}$ & $\begin{array}{l}\text { Pi et al }^{4} 2011 \\
\text { Elmeguid et al } 2013 \\
\text { Bernabei et al }{ }^{10} 2014\end{array}$ \\
\hline $\begin{array}{l}\text { Thyrotropin-Releasing } \\
\text { Hormone (TRH) }\end{array}$ & $\begin{array}{l}\text { Membrane-associated } \\
\text { peptidase (ectopeptidase) and } \\
\text { it cease s peptide-mediated } \\
\text { cell signaling. }\end{array}$ & Yamamoto et $\mathrm{al}^{6} 2012$ \\
\hline $\begin{array}{l}\text { Bone Morphogenic Protein } \\
\text { (BMP-2) }\end{array}$ & $\begin{array}{l}\text { Important in development of } \\
\text { dental pulp , its absence } \\
\text { results in reduced blood } \\
\text { vessels and colligated } \\
\text { pericytes. }\end{array}$ & $\begin{array}{l}\text { Yang et al }{ }^{7} 2012 \\
\text { Malik et al }^{22} 2018 \\
\text { Rakian et } \mathrm{al}^{23} 2013\end{array}$ \\
\hline Bone sialoprotein (BSP) & $\begin{array}{l}\text { Essential for mineralizing } \\
\text { tissues, like bone, cartilage, } \\
\text { dentin } \\
\text { and cementum. }\end{array}$ & Boushell et al $^{8} 2011$ \\
\hline $\begin{array}{l}\text { Pyridinoline cross -linked } \\
\text { carboxyterminal telopeptide } \\
\text { of type I collagen }\end{array}$ & $\begin{array}{l}\text { Type I collagen is the primary } \\
\text { form of collagen present in } \\
\text { mineralized tissues. }\end{array}$ & $\begin{array}{l}\text { Mishra et al }{ }^{9} 2014 \\
\text { Costalonga et al }{ }^{24} 2014\end{array}$ \\
\hline Calprotectin & $\begin{array}{l}\text { Antimicrobial and antifungal, } \\
\text { critical role in inflammation }\end{array}$ & Silva et al ${ }^{11} 2015$ \\
\hline Osteopontin (OPN) & Helps in remodeling bones & Hans et al ${ }^{12} 2012$ \\
\hline
\end{tabular}




\section{Biomarkers in Caries:}

Matrix Metalloproteinases (MMP): After demineralization by bacterial acids, the host cell-derived MMP lead to dentin degradation. Regardless of the periodontal status of the subject, both MMP-1 (interstitial collagenase) and MMP-8 (PMN-collagenase derived) can be quantified in the saliva. MMP-20 is released and its activation takes place during caries progression.

Bone Sialoprotein (BSP): is involved in dentin mineralization and MMP-2 modulation. BSP production during caries goes up by 8 -folds. Both BSP and MMP-2 are involved in the mechanism of host defense which leads to calcification of caries-affected areas.

Alkaline Phosphatase (ALP): leads to early deposition of minerals and the calcification of different tissues. It is also considered as a marker for the odontoblast- like differentiation. Pulp cells show high levels of ALP activity during repair and healing after pulpal injury.

\section{Biomarkers in Reversible Pulpitis:}

Prostaglandin E2: stimulates osteoblasts to release factors that induce osteoclast bone resorption.[13]

Interleukin 1 beta (IL-1beta): is a protein and member of the cytokine interleukin 1 family. It is an essential mediator of the inflammatory response and participates in a number of cellular activities including cell proliferation, differentiation, and apoptosis.

Osteocalcin: is a noncollagenous protein hormone present in bone and dentin.

Inducible Nitric oxide synthase (iNOS): is involved in the inflammatory cycle, releasing vast amounts of NO over a long period of time, with a role in the non-specific immune response and functions as a toxic agent in infections.

CXC chemokine ligand 10 (CXCL10): is a member of the non-ELR CXC family of chemokines and can be induced in a number of cell types, including IFN-stimulated macrophages. In pulpitis, the selective aggregation of lymphocyte subsets into inflamed dental pulp can be regulated by interactions with CXCL10-CXCR[3.]

Human b-defensins (hBDs): play an important role as a first line defense against microorganisms in the oral cavity. They bind preferentially to microbial surfaces through electrostatic and hydrophobic interactions and disrupt their cell layers.
Biomarkers in Irreversible Pulpitis:

Calcitonin gene-related peptide (CGRP): occurs in two types in humans: alpha-CGRP and beta-CGRP, also known as CGRP I and CGRP II. It is a potent peptide vasodilator and can operate in nociception transmission.

Substance P: is a neuropeptide and a primary mediator of inflammation in the dental pulp.[14]

Prostaglandin F2alpha: is a naturally occurring prostaglandin. PGF2alpha works by binding to the F2alpha receptor in prostaglandin.

Interleukin-8 (IL-8): promotes movement of neutrophils into the tissue causing degranulation of the neutrophil, resulting in the release of enzymes causing tissue destruction.

Matrix metalloproteinase-3 (MMP-3): also known as Stromelysin-1, degrades collagen II, III, IV, IX and X, proteoglycans, fibronectin, laminin, and elastin. It is active in healing wounds and reaches cellular nuclei and regulates transcription.

Tumor necrosis factor-alpha (TNF-alpha): is a cell signaling protein (cytokine) that is involved in systemic inflammation during the acute phase. It is produced primarily by activated macrophages, along with many other types of cells, such as CD4 + lymphocytes, NK cells, neutrophils, mast cells, eosinophils, and neurons.

Vascular endothelial growth factor (VEGF): is a signal protein produced by cells which stimulates blood vessel formation. It improves vascular proliferation and permeability.

Manganese superoxide dismutases (Mn-SODs): Reactive oxygen intermediates (ROIs) are a group of oxidant molecules released during inflammatory processes by host cells. These molecules are also formed by incomplete oxygen reduction in the mitochondrial matrix, in relatively small amounts in healthy cells. The manganese SOD (Mn-SOD) is primarily found in the mitochondrial matrix.[15]

C-X-C motif chemokine 10 (CXCL10): also referred to as Interferon gamma-induced protein, is a small cytokine of the CXC family of chemokines. T-cells are most likely the predominant lymphocyte group in inflamed dental pulp tissue. Chemokines are responsible for the recruitment and subsequent activation of particular leukocytes, such as 
activated T-cells, into inflamed tissues through specific chemokine receptors expressed in cells but little is known about the role of chemokines in the aggregation of lymphocytes in the lesion of the dental pulp.

\section{Biomarkers in Asymptomatic apical periodontitis:}

RANKL and Osteoprogerin (OPG): NF-KB ligand receptor activator (RANKL, also known as TRANCE, ODF and OPGL) is a recently identified superfamily member of the tumor necrosis factor, which promotes dendritic cell survival, induces osteoclastic differentiation from hemopoietic precursors leading to bone resorption.16 RANKL's activity is neutralized by binding to its superfamily TNF-receptor decoy osteoprogerin (OPG).

MMP-2 (Gelatinase): is an essential mediator of connective tissue loss in chronic periodontitis.[17]

MMP-9: is a matrixin, belonging to the family of zincmetalloproteinases involved in extracellular matrix degradation.

\section{Biomarkers Symptomatic apical periodontitis:}

Tartrate-resistant acid phosphatase (TRAP or TRAPase): also called acid phosphatase, is a glycosylated monomeric metalloprotein enzyme. Functions of TRAP include osteopontin / bone sialoprotein dephosphorylation, the generation of reactive oxygen species (ROS), iron transport, and cell growth and differentiation.

\section{Biomarkers in Chronic periodontitis:}

MMP-8: its primary function is degradation of collagen type I, II and III. High levels of MMP-8 in gingival crevicular fluid and salivary fluid (SF) have been reported to be associated with seriousness of periodontal disease.[18]

\section{Biomarkers in Periapical abscess:}

Mesenchymal Stem Cells (MSCs): are multipotent stromal cells that can differentiate into a variety of cell types, including osteoblasts, chondrocytes, myocytes and adipocytes. Cell body contains a large, round nucleus with a prominent nucleolus, which is surrounded by finely dispersed chromatin particles, giving the nucleus a clear appearance.

Oxidative stress index: Reactive oxygen species (ROS) generation is a major pathogenic mechanism for diseases that include phagocytic penetration and bone resorption as mechanisms of host defense against the invading pathogen. It is the most important antioxidant molecule present in saliva. 8-isoprostanes: Isoprostanes (IsoP) are stable molecules, found in all human tissues and biological fluids including blood, urine, bronchoalveolar lavage fluid, cerebrospinal fluid and bile.19

\section{Biomarkers in Periapical cysts:}

Chemokines (RANTES, IP-10 and MCP-1): are a family of small proteins $(8-10 \mathrm{kD})$ associated with the migration and activation of leukocytes and selectins, which account for the adhesion of inflammatory cells to the walls of the vessels. High levels of chemokine CXCL12/SDF-1 are found in periapical inflammatory lesions, with $\mathrm{CD} 117+$ mast cells being the main source of the chemokine expressed in this type of lesion.

Cytokines (IL-6): are proteins, secreted in response to microbial agents and other injuries caused by leukocyte recruitment. IL-6 is involved in bone remodeling, activation and differentiation of immune cells and osteoclasts, with macrophages being the main source of periapical cysts.[20,21]

Table 2: Biomarkers of Diseases in Pulp and Periapical Tissue.

\begin{tabular}{|c|c|c|c|c|}
\hline Disease & Sl.no. & Biomarker & Role & Studies \\
\hline \multirow[t]{2}{*}{ Caries } & 1. & $\begin{array}{c}\text { Matrix } \\
\text { Metalloproteinases } \\
\text { (MMP) }\end{array}$ & $\begin{array}{l}\text { Derived from host cells } \\
\text { participate in the destruction of } \\
\text { dentin after bacterial acid } \\
\text { demineralization }\end{array}$ & Tannure et al $\mathrm{al}^{25} 2012$ \\
\hline & 2. & $\begin{array}{c}\text { Alkaline Phosphatase } \\
\text { (ALP) }\end{array}$ & $\begin{array}{l}\text { Repair and heal ing after pulpal } \\
\text { injury }\end{array}$ & Hegde et al $^{26} 2014$ \\
\hline \multirow[t]{3}{*}{$\begin{array}{l}\text { Reversible } \\
\text { Pulpitis }\end{array}$} & 1. & Prostaglandin $\mathrm{E}_{2}$ & $\begin{array}{l}\text { Multiple pro-inflammatory and } \\
\text { immunomodulatory effects }\end{array}$ & Petrini et al $^{13} 2012$ \\
\hline & 2. & $\begin{array}{l}\text { Interleukin } 1 \text { beta (IL- } \\
\text { 1beta) }\end{array}$ & $\begin{array}{l}\text { Regulates immune and } \\
\text { inflammatory reactions; } \\
\text { stimulates bone resorption }\end{array}$ & Subaric et a $\left.\right|^{28} 2017$ \\
\hline & 3. & Osteocalcin & $\begin{array}{l}\text { Regulation of bone } \\
\text { mineralization }\end{array}$ & $\begin{array}{l}\text { Elmeguid et al } \\
2013\end{array}$ \\
\hline \multirow[t]{2}{*}{$\begin{array}{l}\text { Irreversible } \\
\text { Pulpitis }\end{array}$} & 1. & Substance P & $\begin{array}{l}\text { Vasoactive mediator, immune } \\
\text { mediator }\end{array}$ & Sattari et al ${ }^{14} 2010$ \\
\hline & 2. & $\begin{array}{c}\text { Matrix } \\
\text { metalloproteinase-3 } \\
\text { (MMP-3) }\end{array}$ & $\begin{array}{l}\text { Hydrolysis of intercellular } \\
\text { matrix }\end{array}$ & Teja et a ${ }^{30} 2018$ \\
\hline \multirow[t]{2}{*}{$\begin{array}{l}\text { Asymptomatic } \\
\text { Apical } \\
\text { Periodontitis }\end{array}$} & 1. & $\begin{array}{c}\text { RANKL and } \\
\text { Osteoprogerin (OPG) }\end{array}$ & $\begin{array}{l}\text { Promotes dendritic cell } \\
\text { survival, induces osteoclastic } \\
\text { differentiation from } \\
\text { hemopoietic precursors leading } \\
\text { to bone resorption }\end{array}$ & Hanada et al ${ }^{16} 2011$ \\
\hline & 2. & MMP-2 (Gelatinase) & $\begin{array}{l}\text { Hydrolysis of intercellular } \\
\text { matrix }\end{array}$ & $\begin{array}{l}\text { Bhupinder et al } \\
2010\end{array}$ \\
\hline $\begin{array}{c}\text { Chronic } \\
\text { Periodontitis } \\
\end{array}$ & 1. & MMP-8 & $\begin{array}{l}\text { Degradation of collagen type I, } \\
\text { II and III }\end{array}$ & $\begin{array}{l}\text { Borujeni et al } \\
2015\end{array}$ \\
\hline \multirow[t]{2}{*}{$\begin{array}{c}\text { Periapical } \\
\text { Abscess }\end{array}$} & 1. & $\begin{array}{l}\text { Mesenchymal Stem } \\
\text { Cells (MSCs) }\end{array}$ & Tissue repair and regeneration & Estrela et al $^{31} 2019$ \\
\hline & 2. & 8-isoprostanes & $\begin{array}{l}\text { Biological activity as } \\
\text { inflammatory mediators that } \\
\text { augments Pain perception }\end{array}$ & $\begin{array}{l}\text { Raymond et al } \quad{ }^{19} \\
2011\end{array}$ \\
\hline Periapical Cysts & 1. & Cytokines (IL-6) & $\begin{array}{l}\text { Regulator of T - and B -cell } \\
\text { growth, acute phase protein } \\
\text { production }\end{array}$ & $\begin{array}{l}\text { Araujo-Pires et al } \\
2014 \\
\text { Bracks et al }^{21} 2014\end{array}$ \\
\hline
\end{tabular}




\section{Discussion:}

Osteocalcin is the terminal marker of odontoblast differentiation, concentrated in the mantle dentine matrix. It is expressed in response to the preparation of cavities. Elmeguid et al showed that osteocalcin is involved in obturating the dental tubules and maintains the vitality of the dental pulp against external damage or infection after tooth preparation.

Yamamoto et al discovered in the dental pulp, ThyrotropinReleasing Hormone (TRH)-Degrading Enzyme (DE). Palosaari et al found that both odontoblast and pulp tissue express MMP-1, while the expression of MMP-13 was five times more abundant in pulp tissue compared to odontoblasts. Human pulp fibroblasts and osteoblasts express collagenase, that can be stimulated with cytokines, provides evidence that MMPs are involved in controlling protective responses to external irritation in the human dentin - pulp complex. Sulkala et al showed that MMP-20, produced during primary dentinogenesis, is incorporated into the dentine and is released during caries. In the pulp, main cellular source of MMP-20 is the odontoblasts which secrete MMP-20 into the dentinal fluid. Sulkala et al also established that MMP-8 represents the primary human dentin collagenase. The hostderived MMPs present in saliva and dentin are triggered at acidic $\mathrm{pH}$ as a result of release of lactate from cariogenic bacteria.

BMP-2 is essential for production of dental pulp, its deficiency, diminishes blood vessels and pericytes. Malik et al22 found that BMP 2, signals mineralization of the tooth. BMP2 is involved in odontoblast differentiation, through NF$\mathrm{Y}$ signaling during tooth development, was established by Chen et al. Rakian et al23 established role of BMP2, in the development of tooth root and supporting structures, including alveolar bone, CIFC and periodontal ligaments within the periodontium.

Secretion of OPN by immunocompetent cells, leads to differentiation of odontoblast-like cells, resulting in reparative dentin forrmation. Hasegawa et al confirmed production of OPN by Epithelial cell rests of Malassez, during repair of tissue and cementum formation. Secretion of BSP and OPN in periodontal tissues, has been confirmed in studies, during healing, repair and regeneration. With advancement of periodontal disease, Type I collagen Pyridinoline cross-linked carboxyterminal telopeptide level, in the blood increases, confirming its role as biomarker in periodontal diseases. [24]
MMP 20 from odontoblasts secreted during caries, is reparative dentin formation. MMPs and their inhibitors are essential in dentine formation, caries progression, and hybrid layer degradation. Tannure et al25 found that caries is associated with MMP20. MMP9 is the main gelatinase in saliva, gingival crevicular fluid and carious lesions. Boushell et al confirmed secretion of MMP-2 and BSP, by odontoblast as a defense mechanism. Gandhy and Damle found correlation between higher alkaline phosphatase level in rampant caries. Hegde et al26 also found correlation between salivary and serum Alkaline Phosphatase levels, with caries progression, indicating its use as a biochemical marker in caries. Various other studies have also confirmed, higher levels of ALP in caries-active persons.[27]

Silva et al isolated higher level of cytokines, in inflamed pulp than those from healthy pulp. Subaric et al 28 isolated IL1beta in all pulp tissue samples, but highest concentration was found in pulpitis. Sirma et al29 confirmed the essentiality of VEGF and FGF, for the repair of pulp during injury. Sattari et al found a similar pattern of healing with OCN and FGF. OCN is secreted during reversible pulpitis, which correlates to the expression of the MCP-1, MIP-1b, sIL-2ra and MDC as proinflammatory mediators. Thus, it can be safely assumed that OCN partially controls, pulp repair in reversible pulpitis, which diminishes with progression of inflammation and expression of IL-1 alpha and IL-1 beta.

Level of eNOS and iNOS production, in healthy and inflamed pulp varies. eNOS maintains pulpal homeostasis whereas iNOS becomes important in inflammatory pathological processes. In reversible pulpitis found high rate of iNOSproduced, high NO level. The latter being an antimicrobial agent, decreases viability of cariogenic bacteria.

Enhanced production of CGRP takes place in teeth with irreversible pulpitis than those with healthy pulp. Bucheli et al established the activity of CGRP in irreversible pulpitis, that modulates the inflammatory response. Similarly, during irreversible pulpitis, production of Substance P increases. IL8 levels, were found to be higher in exposed pulp and irreversible pulpitis than normal pulps by Elsalhy et al. Teja et al30 found higher level of MMP-3, in inflammatory conditions, due to spread of the infection. Establishing the role of MMPs, in the degradation of the collagenous structure, spread of the pathology and essential in the physiologic tissue remodeling process. Pezelj et al found, TNF-alpha to be produced both in pulp and periapical lesions, thus suggesting their role as marker for assessing level of pulpal 
inflammation. VEGF is involved, in the etiology and progression of pulpitis, has been established by the study of Artese et al, wherein it was confirmed that VGEF is produced in higher levels in irreversible than reversible pulpitis. Bodor et al found higher Mn-SOD mRNA level, in the irreversible pulpitis than the noninflamed pulp, establishing Mn-SODs enzyme activity in inflamed pulp compared to the normal pulp. Adachi et al identified increased level of CXCL10, in inflamed dental pulp tissues, in response to caries related bacteria and pro-inflammatory cytokines, pointing its role in pathogenesis of irreversible pulpitis.

In asymptomatic apical periodontitis, for osteoclast formation and stimulation, RANKL is supposedly the master cytokine. According to Dezerega et al, oxidative imbalance along with enhanced level of MMP-9 and MMP-2 is important, in the development and/or progression of asymptomatic apical periodontitis. Tartrate-resistant acid phosphatase (TRAP)-5, an enzyme released along with bone matrix degradation products by active osteoclasts, represents a biomarker of osteoclastic activity and bone resorption. Munoz et al found higher TRAP-5 levels, in symptomatic apical periodontitis compared with asymptomatic lesions and healthy controls. Estrela et al31 found Periapical lesions were found to be a rich source of Mesenchymal Stem Cells (MSCs), with secretion of CD44, CD73, and CD105 markers and absence of CD45 secretion, by Estrela et al. Periapical abscesses have higher amount of MSCs in compared to periapical cysts and granulomas, pointing towards the fact that acute inflammatory lesions, harbor cells that have the potential to influence cell proliferation, in periapical area.

In both primary and secondary apical periodontitis, periapical abscess and pulpitis, Vengerfeldt et al found OxS to play an important role in pathologic mechanism, at local and systemic level.

Silva et al found periapical granuloma in comparison to periapical cyst to display higher CD4+ and CD8+ cells, along with RANTES, IP-10, and MCP-1. Periapical granuloma also display higher activity of MMP-9 and MMP-13 than radicular cysts. Gervasio et al isolated IL-6 in $92.8 \%$ of cyst fluid and $86.4 \%$ of the studied tissue samples, indicating its importance in their pathogenesis. Martinho et al established, correlation between the size of the radiologic image of periapical cysts and IL-6 levels, indicating the latter's role, in bone resorption process within periapical cyst.

\section{Conclusion:}

Healthy and diseased pulp and periapical tissue, tend to reflect physiologic and pathologic agents, which on isolation and estimation, can help diagnose, the condition more conclusively. Use of these agents, along with signs, symptoms, result of various tests, can aid in establishing the condition, more precisely.

\section{References:}

1. Ricucci D, Loghin S, Siqueira JF Jr, Correlation between clinical and histologic pulp diagnoses. J Endod. 2014;40:1932-1939.

2. Rechenberg DK, Zehnder M. Molecular diagnostics in endodontics. Endod Topics. 2014; 30:51-65.

3. Mejare IA, Axelsson S, Davidson T, Frisk F, Hakeberg M. Diagnosis of the condition of the dental pulp: A systematic review. Int Endod J. 2012;45:597-613.

4. Pi M, Wu Y, Quarles LD. GPRC6A mediates responses to osteocalcin in ?-cells in vitro and pancreas in vivo. Journal of Bone and Mineral Research. 2011;26(7):1680-3.

5. Elmeguid A, Abdeldayem M, Kline LW. Osteocalcin expression in pulp inflammation. J Endod. 2013;39:865-872.

6. Yamamoto T, Murukami M, Ishizaka R, Iohara K, Kurita K. Identification of thyrotropin-releasing hormone (TRH)- degrading enzyme as a biomarker for dental pulp tissue. Dentistry. 2012;2(1):114119.

7. Yang W, Harris MA, Cui Y, Mishina Y, Harris SE, Gluhak-Heinrich J. BMP2 is required for odontoblast differentiation and pulp vasculogenesis. J Dent Res. 2012;91:58-64.

8. Boushell LW, Nagaoka H, Nagaoka H, Yamauchi M. Increased matrix metalloproteinase-2 and bone sialoprotein response to human coronal caries. Caries Res. 2011;45:453-459.

9. Mishra D, Gopalakrishnan S, Arun KV. Evaluation of Salivary Levels of Pyridinoline Cross Linked Carboxyterminal Telopeptide of Type I Collagen (ICTP) in Periodontal Health and Disease. J Clin Diagn Res. 2015;9(9):ZC50-ZC55.

10. Bernabei R, Martone AM, Ortolani E, Landi F, Marzetti E. Screening, diagnosis and treatment of osteoporosis: A brief review. Clin Cases Miner Bone Metab 2014;11:201-7.

11. Silva N, Abusleme L, Bravo D. Host response mechanisms in periodontal diseases. Journal of Applied Oral Science. 2015;23(3):329355.

12. Hans S, Mali AM. Estimation and comparison of osteopontin levels in plasma in subjects with healthy periodontium and generalized chronic periodontitis and its assessment after scaling and root planing. J Indian Soc Periodontol. 2012;16:354-357.

13. Petrini M, Ferrante M, Ciavarellp C, Ceccarinp A. Prostaglandin E2 to diagnose between reversible and irreversible pulpitis. International journal of immunopathology and pharmacology. 2012;25(1):157-163.

14. Sattari M, Mozayeni MA, Matloob A, Mozayeni M, Javaheri HH. Substance $P$ and CGRP expression in dental pulps with irreversible pulpitis. Aust Endod J. 2010;36(2):59-63

15. Ka S, Hirai J, Yasukawa T, Nakahara Y, Inoue YH . A correlation of reactive oxygen species accumulation by depletion of superoxide dismutases with age-dependent impairment in the nervous system and muscles of Drosophila adults. Biogerontology. 2015;16(4):485-501.

16. Hanada R, Hanada T, Sigl V, Schramek D, Penninger JM. RANKL/RANK-beyond bones. J Mol Med. 2011;89(7):647-56. 
17. Bhupinder SS. Matrix metalloproteinases-an overview. Research and Reports in Biology. 2010;1:1-20.

18. Borujeni S, Mayer M, Eickholz P. Activated matrix metalloproteinase8 in saliva as diagnostic test for periodontal disease? A casecontrol study. Med Microbiol Immunol. 2015;204:665-672.

19. Raymond C S, Chung-Yung J, Wai M, Shan H, Amy M.L. Biomarkers of oxidative damage in cigarette smokers: Which biomarkers might reflect acute versus chronic oxidative stress? Free Radical Biology and Medicine. 2011;50(12):1787-1793.

20. Araujo-Pires AC, Francisconi CF, Biguetti CC.Simultaneous analysis of T helper subsets (Th1, Th2, Th9, Th17, Th22, Tfh, Tr1 and Tregs) markers expression in periapical lesions reveals multiple cytokine clusters accountable for lesions activity and inactivity status. J Appl Oral Sci. 2014;22:336-346.

21. Bracks IV, Armada L, Gonc, alves LS. Distribution of mast cells and macrophages and expression of interleukin-6 in periapical cysts. J Endod. 2014;40:63-68.

22. Malik Z, Alexiou M, Hallgrimsson B, Economides AN, Luder HU, Graf D. Bone Morphogenetic Protein 2 Coordinates Early Tooth Mineralization. J Dent Res. 2018;97(7):835-843.

23. Rakian A, Yang WC, Heinrich JG, Cui Y, Harris MA. Bone morphogenetic protein-2 gene controls tooth root development in coordination with formation of the periodontium. Int $\mathrm{J}$ Oral Sci. 2013;5(2):75-84.

24. Costalonga M, Herzberg MC. The oral microbiome and the immunobiology of periodontal disease and caries. Immunol Lett. 2014;162(2):22-38.

25. Tannure PN, Kuchler EC,Lips A, Castro MD, Luiz RR, Granjeiro JM, Vieira AR. Genetic Variation in MMP20 Contributes to Higher Caries Experience. J Dent. 2012;40(5):381-386.

26. Hegde MN, Wali A, Punja A, Shetty C. Correlation Between Dental Caries and Alkaline Phosphatase and Calcium Levels in Serum and Saliva in Adult Indian Population. Indo American Journal Of Pharm Research. 2014;4(04):2178-2182.

27. Hegde MN, TahilianiT, Shetty S, Devadiga D. Salivary alkaline phosphatase and calcium in caries-active type II diabetes mellitus patients: An in vivostudy. Clin Dent. 2014;5(4):440-444.

28. Subaric L, Mitic A, Matvijenko V, Jovanovic R, Zivkovic D. Interleukin 1-beta analysis in chronically inflamed and healthy human dental pulp. Vojnosanit Pregl. 2017;74(3):256-260.

29. Sirma A. Association Between Clinical, Para-Clinical and Environmental Indicators for Tooth Decay in Children with Pyelonephritis. Adv Dent \& Oral Health. 2019;10(4):134-139.

30. Teja KV, Ramesh S, Priya V. Regulation of matrix metalloproteinase-3 gene expression in inflammation: A molecular study. J Conserv Dent. 2018;21(6):592-596.

31. Estrela C, Souza PO, Barbosa MG, Carvalhosa AA, Batista AC. Mesenchymal Stem Cell Marker Expression in Periapical Abscess. J. Endod. 2019;45(6):716-722. 